\title{
Finger Stick
}

National Cancer Institute

\section{Source}

National Cancer Institute. Finger Stick. NCI Thesaurus. Code C85551.

A procedure in which a finger is pricked with a lancet to obtain a small quantity of capillary blood for testing. 